\title{
Perspectivas para un cooperativismo socialista integral con base en los valores y principios promovidos por la constitución cubana
}

\author{
(Perspectives for a Comprehensive Socialist Cooperativism \\ Based on the Values and Principles Promoted by \\ the Cuban Constitution)
}

Héctor Mata Diestro ${ }^{1}$

Abogado

Sumario: I. Introducción. II. Los principios y valores del cooperativismo en clave socialista. III. Una interpretación garantista y potenciadora del derecho de asociación cooperativa como base para un desarrollo integral del cooperativismo en Cuba. IV. Marco constitucional cubano para un cooperativismo socialista integral. $\mathrm{V}$. Formas asociativas para la diversificación y perfeccionamiento del sector cooperativo. VI. Conclusiones. Bibliografía.

Resumen. Se propone una interpretación garantista del texto constitucional cubano, que permita un desarrollo efectivo e integral del fenómeno cooperativo en Cuba, en el marco del proceso de actualización de su modelo socioeconómico, recurriendo a los valores y principios promovidos por la Constitución cubana, en relación a la identidad cooperativa, como base primaria de la interpretación.

Palabras clave: cooperativa, identidad, perspectivas, constitución.

Abstract. In this thesis a guarantee-based interpretation of the cuban constitutional text is proposed. The main aim of this interpretation is to enable the effective and comprehensive developement of the cooperative phenomena in Cuba in the context of the update process of Cuban socioeconomic status. To fulfil this objective, and as a primary basis of this interpretation, the values and principles promoted by the Cuban Constitution have been considered and at the same time they have been associated to the cooperative relations.

Keywords: cooperative, identity, perspectives, constitution.

1 Licenciado en Derecho. Investigador del grupo de investigación de la Universidad de Deusto y reconocido por el Gobierno Vasco «Cooperativismo, fiscalidad, fomento, relaciones laborales y protección social» (IT1089-16). E-mail: hector.mata@opendeusto.es 


\section{Introducción}

En el marco del proceso de actualización del modelo socioeconómico, en el que el Estado socialista cubano se encuentra, han surgido nuevas formas de desarrollo cooperativo en diversos sectores de la economía nacional. Para tal fin, en abril del año 2011, el VI Congreso del Partido Comunista de Cuba (PCC) aprobó los denominados Lineamientos de la Política Económica y Social del Partido y la Revolución², con la intención de sentar las bases para el proceso de actualización del modelo económico socialista, cuyos puntos 25 a 29, agrupados bajo el título de "Las cooperativas», fijaban pautas para su inserción en el nuevo modelo.

En este sentido y atendiendo a los datos publicados por la Oficina Nacional de Estadística e Información (ONEI), en marzo de 2019 existían en el país 434 Cooperativas No Agropecuarias (CNA), vinculadas a actividades tales como la industria manufacturera, la construcción, el transporte, el comercio, la hostelería, la restauración o el suministro de electricidad, gas y agua ${ }^{3}$. Hasta ese momento, la Constitución socialista de 1976, a pesar de sus diversas modificaciones, había reconocido a la cooperativa, de manera expresa, solo en la esfera agropecuaria de la economía 4 .

No obstante, el 10 de abril de 2019 fue publicada la nueva Constitución de la República de Cuba, la cual vino a reconocer a la cooperativa sin limitarla a ningún sector económico concreto. A pesar de ello, en la actualización del modelo socioeconómico cubano, el cooperati-

2 PCC: Lineamientos de la Política Económica y Social del Partido y la Revolución. Aprobados el 18 de abril de 2011. Disponibles en: http://www.cubadebate.cu/noticias /2011/05/09/descargue-en-cubadebate-los-lineamientos-de-la-politica-economica-ysocial-pdf/\# .XMrZhtSLRnL; última consulta: 24-03-2020.

3 ONEl: Organización Institucional. Principales Entidades. Enero-Marzo 2019, Oficina Nacional de Estadísticas e Información, La Habana, 2019, pp. 5 y 12.

4 Artículo 20: Los agricultores pequeños tienen derecho a asociarse entre sí, en la forma y con los requisitos que establece la ley, tanto a los fines de la producción agropecuaria como a los de obtención de créditos y servicios estatales. Se autoriza la organización de cooperativas de producción agropecuaria en los casos y en la forma que la ley establece. Esta propiedad cooperativa es reconocida por el Estado y constituye una forma avanzada y eficiente de producción socialista. Las cooperativas de producción agropecuaria administran, poseen, usan y disponen de los bienes de su propiedad, de acuerdo con lo establecido en la ley y en sus reglamentos. Las tierras de las cooperativas no pueden ser embargadas ni gravadas y su propiedad puede ser transferida a otras cooperativas o al Estado, por las causas y según el procedimiento establecido en la ley. El Estado brinda todo el apoyo posible a esta forma de producción agropecuaria. Constitución de la República de Cuba. Gaceta Oficial de la República de Cuba, Edición Extraordinaria núm. 3, de 31 de enero de 2003. 
vismo continúa encontrando obstáculos en su desarrollo. Motivo por el cual, debe prevalecer una interpretación garantista y potenciadora del derecho de asociación cooperativa, en coherencia con la inspiración socialista del propio texto constitucional, que permita un desarrollo integral del fenómeno cooperativo.

En este artículo se afrontan desde distintos prismas, incluido el constitucional, la forma de afrontar su encaje jurídico respetando, como no podía ser de otra manera, el marco normativo vigente.

Para dar respuesta a dichos planteamientos, se han analizado y estudiado importantes trabajos históricos y doctrinales en busca de una perspectiva integral del concepto cooperativista en una clave eminentemente socialista, llegando a una serie de conclusiones que quedan reflejadas al final de este trabajo de investigación.

\section{Los principios y valores del cooperativismo en clave socialista}

El cooperativismo moderno nació en la misma época en la que también se concretaron el sindicalismo y el socialismo, impulsado por la misma concepción de vida y las mismas aspiraciones emancipatorias, y siempre en la búsqueda de soluciones superadoras de la situación existente para la clase obrera; compartiendo, desde su origen, una misma identidad 5 .

De hecho, la cooperación fue concebida en un inicio por Robert Owen, uno de los máximos exponentes del socialismo utópico o premarxista, como un sinónimo de socialismo ${ }^{6}$. Cuestión que desarrolla LAMPERT en su obra La doctrina cooperativa ${ }^{7}$.

En la actualidad, derivados de las normas que acordaron para sí los llamados «Pioneros de Rochdale», la Alianza Cooperativa Internacio-

5 Mata Diestro, H.: «Fondos sociales obligatorios: la justificación de su irrepartibilidad en los orígenes del cooperativismo y del movimiento obrero organizado», Boletín de la Asociación Internacional de Derecho Cooperativo, núm. 53, 2018, p. 295.

6 Lichtheim, G.: Breve historia del socialismo, Alianza Editorial, Madrid, 1970, pp. 56-57.

7 «La misma palabra «socialismo» en el sentido de doctrina económica, se utilizó por primera vez en Inglaterra en 1821-22 en la correspondencia de Robert Owen y sus amigos, y después en 1833, en un artículo del periódico "The poor man's Guardian» («El guardián del hombre pobre»). El índice de la colección del «New Moral World» del 20 de febrero de 1836 decía: "Socialism: alias Owenism». El socialismo es, pues, en su origen, sinónimo de owenismo, la doctrina del padre de la cooperación integral». LAMBERT, P.: La doctrina cooperativa, Intercoop Editora Cooperativa Limitada, Buenos Aires, 1970, p. 31. 
nal $(\mathrm{ACl})$, identifica los principios y valores del cooperativismo a nivel mundial, fijando en cierta manera, cuáles han de ser las características esenciales que han de determinar la idiosincrasia de la sociedad cooperativa, diferenciándola de las empresas de naturaleza eminentemente capitalista. No obstante, resulta preciso advertir que, cada cooperativa, constituye una realidad concreta y determinada, sujeta a condicionantes de tipo cultural, económico, histórico, político y social, que la particularizan respecto de otras sociedades análogas.

A su vez, «la relación dialéctica entre la propuesta cooperativa y la socialista, la cual se vio favorecida en origen, explica la influencia de las ideas socialistas en la fijación de los denominados «Principios de Rochdale». Una relación que, si bien puede haberse visto desfavorecida, cuando, en apariencia, ambas discurrían por caminos diferentes, aparece en la revisión y reformulación de estos principios por parte de la cooperación organizada. Relación dialéctica que se ve favorecida nuevamente, cuando los principios organizativos del cooperativismo cumplen con su máxima y más vieja aspiración, aquella de «cooperativizar la organización económica y social», conectando, al mismo tiempo, con el ideario de Marx, Engels y Lenin» 8 .

Estos principios y valores cooperativos son también acordes con el carácter socialista de la Constitución cubana, al igual que lo eran respecto al texto constitucional de $1976^{9}$, cuyo Preámbulo continua haciendo referencia a «las ideas de emancipación social de Marx, Engels y Lenin» ${ }^{10}$.

8 Mata Diestro, H.: «Identidad cooperativa y economía socialista. Apuntes en torno a la relación dialéctica entre cooperativismo y socialismo». Ponencia presentada en el II Taller Internacional de Derecho Cooperativo, Universidad Hermanos Saíz Montes de Oca, Pinar del Río, Cuba, 2018.

9 Martínez Etxeberria, G. y Mata Diestro, H.: «Perspectivas para un cooperativismo socialista integral con base en los valores y principios promovidos por la Constitución cubana», en VV.AA.: Apuntes de Derecho Cooperativo para Cuba (RodríGuez MusA, O. y Hernández Aguilar, O., coordinación), Ediciones Loynaz, Pinar del Rio, 2018, p. 112.

10 Preámbulo: NOSOTROS, EL PUEBLO DE CUBA, inspirados en el heroísmo y patriotismo de los que lucharon por una Patria libre, independiente, soberana, democrática, de justicia social y solidaridad humana, forjada en el sacrificio de nuestros antecesores; por los aborígenes que se resistieron a la sumisión; por los esclavos que se rebelaron contra sus amos; por los que despertaron la conciencia nacional y el ansia cubana de patria y libertad; por los patriotas que a partir de 1868 iniciaron y participaron en nuestras luchas independentistas contra el colonialismo español, y a los que en el último impulso de 1895 les fuera frustrada la victoria al producirse la intervención y ocupación militar del imperialismo yanqui en 1898; por los que lucharon durante más de cincuenta años contra el dominio imperialista, la corrupción política, la falta de derechos y libertades populares, el desempleo, la explotación impuesta por capitalistas, terratenientes y otros males sociales; por los que promovieron, integraron y desarrollaron las primeras 
De forma más concreta y en relación a las cooperativas obreras de producción, MARX destacó como en ellas «aparece abolido el antagonismo entre el capital y el trabajo (...) bajo una forma en que los obreros asociados son sus propios capitalistas, es decir, emplean los medios de producción para valorizar su propio trabajo», concibiéndolas como una forma de transición entre el modo de producción capitalista y el de producción asociada ${ }^{11}$. En la misma senda de desarrollo ideológico, defendió que la organización socialista de todo el trabajo resultaría del proceso revolucionario de transformación social, en el cual las cooperativas de producción surgirían bajo iniciativa obrera ${ }^{12}$. Lo que le llevo a considerar, como un sinónimo de comunismo, la sustitución del sis-

organizaciones de obreros, campesinos y estudiantes; difundieron las ideas socialistas y fundaron los primeros movimientos revolucionarios, marxistas y leninistas; por los integrantes de la vanguardia de la Generación del Centenario del natalicio de Martí, que nutridos por su magisterio nos condujeron a la victoria revolucionaria popular de enero de 1959; por los que, con el sacrificio de sus vidas, defendieron la Revolución y contribuyeron a su definitiva consolidación; por los que masivamente cumplieron heroicas misiones internacionalistas; por la resistencia épica y unidad de nuestro pueblo; GUIADOS por lo más avanzado del pensamiento revolucionario, antiimperialista y marxista cubano, latinoamericano y universal, en particular por el ideario y ejemplo de Martí y Fidel y las ideas de emancipación social de Marx, Engels y Lenin; APOYADOS en el internacionalismo proletario, en la amistad fraternal, la ayuda, la cooperación y la solidaridad de los pueblos del mundo, especialmente los de América Latina y el Caribe; DECIDIDOS a llevar adelante la Revolución del Moncada, del Granma, de la Sierra, de la lucha clandestina y de Girón, que sustentada en el aporte y la unidad de las principales fuerzas revolucionarias y del pueblo conquistó la plena independencia nacional, estableció el poder revolucionario, realizó las transformaciones democráticas e inició la construcción del socialismo; CONVENCIDOS de que Cuba no volverá jamás al capitalismo como régimen sustentado en la explotación del hombre por el hombre, y que solo en el socialismo y en el comunismo el ser humano alcanza su dignidad plena; CONSCIENTES de que la unidad nacional y el liderazgo del Partido Comunista de Cuba, nacido de la voluntad unitaria de las organizaciones que contribuyeron decisivamente al triunfo de la Revolución y legitimado por el pueblo, constituyen pilares fundamentales y garantías de nuestro orden político, económico y social; IDENTIFICADOS con los postulados expuestos en el concepto de Revolución, expresado por nuestro Comandante en Jefe Fidel Castro Ruz el 1ro. de mayo del año 2000; DECLARAMOS nuestra voluntad de que la ley de leyes de la República esté presidida por este profundo anhelo, al fin logrado, de José Martí: "Yo quiero que la ley primera de nuestra República sea el culto de los cubanos a la dignidad plena del hombre»; ADOPTAMOS por nuestro voto libre y secreto, mediante referendo popular, a ciento cincuenta años de nuestra primera Constitución mambisa, aprobada en Guáimaro el 10 de abril de 1869, la siguiente: CONSTITUCIÓN. Constitución de la República de Cuba. Gaceta Oficial de la República de Cuba, Edición Extraordinaria núm. 5, de 10 de abril de 2019.

11 MarX, K.: El Capital, Libro III, Tomo II, Editorial Akal, Madrid, 2000, pp. 147 y 148.

12 MarX, K.: "Crítica del programa de Gotha», en MArX, K. y Engels, F.: Obras escogidas, Tomo III, Editorial Progreso, Moscú, 1980, pp. 21 y 22. 
tema capitalista por un sistema de producción cooperativa en el que la agrupación de todas las cooperativas mediante una gran unión, regularía la producción nacional con arreglo a un plan común, tomándola bajo su control y poniendo, de esta forma, fin al caos constante y a las convulsiones periódicas, que resultan inherentes al modo de producción capitalista ${ }^{13}$.

En la misma línea ideológica, ENGELS se mostró partidario de «abolir el trabajo asalariado, y con él las diferencias de clase, implantando la producción cooperativa en la industria y en la agricultura en una escala nacional» ${ }^{14}$. Y concibió a las cooperativas «como medidas de transición, para que la sociedad pudiera organizarse de manera íntegramente comunista» ${ }^{15}$.

Posteriormente, LENIN atribuyo a la organización cooperativa «una importancia verdaderamente extraordinaria», "gigantesca e inabarcable», tras el triunfo de la Revolución de Octubre (1917) en el que el derrocamiento de la clase explotadora constituía ya un hecho, y «mucho de lo que parecía fantástico, incluso romántico y hasta trivial en los sueños de los viejos cooperativistas, se convierte ahora en una realidad de lo más natural» ${ }^{16}$. Por ello, añadía, "dado que en nuestro país el poder del Estado se encuentra en manos de la clase obrera y que a este poder estatal pertenecen todos los medios de producción, sólo nos queda, en realidad, por cumplir la tarea de organizar a la población en cooperativas»; pues con «la máxima organización de los trabajadores en cooperativas», decía, "alcanza por sí mismo su objetivo ese socialismo» ${ }^{17}$.

Por ello, el líder de la Revolución de Octubre se mostro partidario de «edificar la sociedad socialista completa, partiendo de las cooperativas», mediante una "revolución cultural», que permitiera participar activamente a toda la población; pues, decía, «si pudiéramos organizar en cooperativas a toda la población, pisaríamos ya con ambos pies terreno socialista» ${ }^{18}$. Así, concluía LenIN: "cuando los medios de producción pertenecen a la sociedad, cuando es un hecho el triunfo de clase del proletariado sobre la burguesía, el régimen de los cooperativistas

13 Marx, K.: «La guerra civil en Francia», en MArX, K. y Engels, F.: Obras escogidas, Tomo II, Editorial Progreso, Moscú, 1979, pp. 194 y 197.

14 Engels, F.: «Carta a A. Bebel», en MarX, K. y Engels, F.: Obras escogidas, Tomo III, Editorial Progreso, Moscú, 1980, p. 31.

15 ENGELS, F.: «Del socialismo utópico al socialismo científico», en MARX, K. y ENGELS, F.: Obras escogidas, Tomo III, Editorial Progreso, Moscú, 1980, pp. 131 y 132.

16 LENIN, V.I.: «Sobre las cooperativas», en LeNIN, V.I.: Sobre las cooperativas, Editorial Progreso, Moscú, 1980, p. 28.

17 Loc. cit.

18 Ibidem, pp. 29-39. 
cultos es el socialismo» ${ }^{19}$. Asimismo, estableció una serie de principios cooperativos que, especificidades socioeconómicas aparte, presentan una gran similitud con los establecidos por la propia $\mathrm{ACl}^{20}$.

De este modo, podemos concluir que entre cooperativismo y socialismo, puede haber diferencia de métodos, pero el fin y el ideal serían el mismo21.

Para concluir este apartado, decir que los principios cooperativos contemplados en el artículo sexto22 del Decreto-Ley núm. 366, de las

19 Ibidem, p. 31.

20 «1. Principio de voluntariedad: Se basa en que el tránsito hacia formas cooperativas ha de producirse voluntariamente. 2. Principio de la ayuda y apoyo del Estado socialista: Lenin enfatizaba sobre el apoyo material y financiero a las cooperativas, insistiendo en que éstas debían ser dotadas de medios que les permitiesen incrementar la productividad del trabajo y poder demostrar su superioridad respecto a la parcela individual. 3. Principio del desarrollo gradual del movimiento cooperativo: el desarrollo gradual es una constante del histórico en general ya que ha de expresarse mediante la evolución de formas más simples a formas superiores de cooperación. 4. Principio de la transformación económica y el progreso social: Representa la conjugación de la política económica-social del partido y el gobierno con los intereses del campesinado, transformándole radicalmente la vida del mismo. 5. Principio de la atención a las condiciones concretas de cada país: Abarca todos los ámbitos de la vida social, económica, política y cultural, los que se tendrán en cuenta para establecer las vías del proceso de cooperación agraria. 6. Principio de la democracia cooperativista: Se basa en el análisis con la participación de todos sus miembros de las cuestiones más importantes, que afectan la vida de esta organización y las decisiones que al respecto se tomen han de ser de común acuerdo. 7. Principio de la unión de los intereses personales con los colectivos en la cooperativa: Lleva implícito la unión de estos últimos con los de toda la sociedad». Moreno Carvajal, T.; Medina Castillo, Y. M.; Medina, H. y Macias, L.: «La cooperativa agropecuaria cubana: valoración de sus presupuestos legales y funcionamiento». Disponible en: https://www.monografias.com/trabajos98/cooperativa-agropecuaria-cubanavaloracion-sus-presupuestos-legales-y-funcionamiento/cooperativa-agrop pecuariacubana-valoracion-sus-presupuestos-legales-y-funcionamiento.shtml\#conclusioa; última consulta: 27-03-2020.

21 «Si la palabra socialismo es tomada en un sentido puramente económico [en cuanto a transformación económica de la sociedad conseguida por la apropiación colectiva de los medios de producción y de cambio], cooperación y socialismo serían sinónimos, y tanto uno como otro término podrían ser empleados indistintamente, siendo el fin y el ideal el mismo. (...) entre el cooperativismo y el socialismo hay diferencia de métodos, y comprensión diferente de los medios de instauración [necesidad o no de conquistar el poder político por parte de la clase obrera]». PoIsson, E.: «La República Cooperativa», Editorial Cervantes, Barcelona, 1921, p. 126.

22 Artículo 6: Las cooperativas se rigen por los principios siguientes: a) voluntariedad: la incorporación y permanencia de los socios en la cooperativa es libre y voluntaria; b) cooperación y ayuda mutuas: todos los socios trabajan y se prestan ayuda y colaboración entre sí para alcanzar los objetivos de la cooperativa; c) decisión colectiva e igualdad de derechos de los socios: la vida económica y social de la cooperativa se analiza y decide de forma colectiva y las decisiones se adoptan democráticamente por los 

los postulados aprobados por la $\mathrm{ACl}^{23}$.

\section{Una interpretación garantista y potenciadora del derecho de asociación cooperativa como base para un desarrollo integral del cooperativismo en Cuba}

El paradigma garantista «propone tanto la crítica como la superación de la brecha entre las normas y la realidad», otorgando un papel protagónico a los derechos fundamentales ${ }^{24}$. Por cuanto, estos últimos, «se expresan en el derecho como principios jurídicos que pretenden garantizar ciertos bienes o valores estipulados en el pacto, empero, a su vez buscan orientar el ordenamiento jurídico y proyectarse sobre

socios, que tienen iguales derechos y obligaciones; todos los socios aportan su trabajo a la cooperativa; d) autonomía y sustentabilidad económicas: la cooperativa tiene independencia económica, disponiendo libremente de su patrimonio dentro de los límites que fija la ley; cubre todas las obligaciones contraídas con sus ingresos; paga los tributos que corresponda; crea fondos y reservas y genera utilidades que se distribuyen entre sus socios en proporción a la contribución al trabajo; e) disciplina cooperativista: los socios conocen, cumplen y acatan de manera consciente las disposiciones y los estatutos que regulan su actividad; cumplen disciplinadamente los acuerdos adoptados en los órganos de dirección y administración, así como las demás regulaciones que sean de aplicación a la cooperativa; f) responsabilidad social, contribución al desarrollo planificado de la economía y al bienestar de los socios y sus familiares. Los planes de la cooperativa tienen como objetivo contribuir al desarrollo económico y social sostenible de la nación desde el ámbito territorial donde realiza sus actividades, proteger el medio ambiente, desarrollar su objeto social sin ánimo especulativo y garantizar el cumplimiento disciplinado de las obligaciones fiscales y otras. Los socios trabajan para fomentar una cultura cooperativista y satisfacer sus necesidades materiales, de capacitación, sociales, culturales, morales y espirituales, así como la de sus familiares y la comunidad; g) colaboración y cooperación entre cooperativas y otras entidades: las cooperativas se relacionan entre sí y con otras entidades, estatales o no, mediante contratos, convenios de colaboración, intercambio de experiencias y otras actividades lícitas; y h) educación y formación: la cooperativa ofrece formación a sus miembros en las actividades a desarrollar con el fin de que estas se realicen con eficacia, eficiencia y calidad; igualmente educa a todos los miembros en los principios del cooperativismo y asegura su formación, particularmente a los que ocupan cargos en la dirección y administración de la cooperativa, para que adquieran o mejoren su gestión administrativa y liderazgo. Decreto-Ley núm. 366, de las Cooperativas No Agropecuarias. Gaceta Oficial de la República de Cuba, núm. 63, de 30 de agosto de 2019.

23 Campos Pérez, Y.; García Pedraza, L. y Martínez Massip, A.: «Las Cooperativas No Agropecuarias en Cuba: su trascendencia socioeconómica y jurídica», Deusto Estudios Cooperativos, núm. 14, 2019, p. 69.

24 ToRres Ávila, J.: "La teoría del Garantismo: poder y constitución en el Estado contemporáneo», Revista de Derecho, núm. 47, 2017, pp. 141 y 164. 
él»; convirtiéndose en «un límite estructural que vincula a todos los poderes públicos en virtud de la supremacía constitucional» ${ }^{25}$. Tal y como recoge la propia Constitución cubana ${ }^{26}$.

Por otro lado, en lo que a la garantía y protección de los derechos fundamentales se refiere, debe de adoptarse una interpretación que potencie los mismos, dado que, en la relación entre el derecho y su posible límite, el criterio de interpretación que debe prevalecer es el de mayor amplitud posible del derecho y la restricción del límite a lo necesario. Teniendo en cuenta que, ningún texto constitucional puede contener una regulación exhaustiva de cada uno de los derechos reconocidos en ella; y tanto los principios como los valores constitucionales, constituyen base primaria para su interpretación y aplicación.

\section{Marco constitucional cubano para un cooperativismo socialista integral}

La nueva Constitución de la República de Cuba reconoce, entre otras formas de propiedad, a la cooperativa «sustentada en el trabajo colectivo de sus socios propietarios y en el ejercicio efectivo de los principios del cooperativismo» ${ }^{27}$.

25 Ibidem, p. 148.

26 Artículo 7: La Constitución es la norma jurídica suprema del Estado. Todos están obligados a cumplirla. Las disposiciones y actos de los órganos del Estado, sus directivos, funcionarios y empleados, así como de las organizaciones, las entidades y los individuos se ajustan a lo que esta dispone. Constitución de la República de Cuba. Gaceta Oficial de la República de Cuba, Edición Extraordinaria núm. 5, de 10 de abril de 2019.

27 Artículo 22: Se reconocen como formas de propiedad, las siguientes: a) socialista de todo el pueblo: en la que el Estado actúa en representación y beneficio de aquel como propietario; b) cooperativa: la sustentada en el trabajo colectivo de sus socios propietarios y en el ejercicio efectivo de los principios del cooperativismo; c) de las organizaciones políticas, de masas y sociales: la que ejercen estos sujetos sobre los bienes destinados al cumplimiento de sus fines; d) privada: la que se ejerce sobre determinados medios de producción por personas naturales o jurídicas cubanas o extranjeras; con un papel complementario en la economía; e) mixta: la formada por la combinación de dos o más formas de propiedad; f) de instituciones y formas asociativas: la que ejercen estos sujetos sobre sus bienes para el cumplimiento de fines de carácter no lucrativo; g) personal: la que se ejerce sobre los bienes que, sin constituir medios de producción, contribuyen a la satisfacción de las necesidades materiales y espirituales de su titular. Todas las formas de propiedad sobre los medios de producción interactúan en similares condiciones; el Estado regula y controla el modo en que contribuyen al desarrollo económico y social. La ley regula lo relativo al ejercicio y alcance de las formas de propiedad. Constitución de la República de Cuba. Gaceta Oficial de la República de Cuba, Edición Extraordinaria núm. 5, de 10 de abril de 2019. 
Como señala Rodríguez Musa, «la nueva Constitución cubana de 2019, pese a la inercia de reducir la naturaleza jurídica de la cooperativa a «forma de propiedad» y a la parquedad que manifiesta respecto a los fines de la institución y a los principios que deben guiar su funcionamiento, abre una puerta al legislador para institucionalizar un movimiento socioeconómico que supere las limitaciones que hasta ahora presenta» ${ }^{28}$.

De este modo, la interpretación garantista y potenciadora del derecho de asociación cooperativa devendría como consecuencia del surgimiento de la institución y su posterior reconocimiento constitucional, en sectores de la economía diferentes al tradicional sector agropecuario, como parte del proceso de actualización del modelo socioeconómico cubano; en cumplimiento de las obligaciones del Estado socialista, el cual, como fija el artículo 13, debe «encauzar los esfuerzos de la nación en la construcción del socialismo», "garantizar la igualdad efectiva en el disfrute y ejercicio de los derechos», "así como preservar y multiplicar los logros alcanzados por la Revolución».

El sustento constitucional anteriormente referido, lo podemos encontrar, al margen del previamente referenciado artículo, en el Preámbulo y los artículos $1,3,4,7,18,19,20,22,23,24,30,31,41,42$, $43,44,65$ y 229. Cuya interpretación debe hacerse conforme a los principios socialistas promovidos por la propia constitución, como son la supresión de «la explotación del hombre por el hombre» y «de cada cual según su capacidad, a cada cual según su trabajo», este ultimo recogido en el artículo 65 del texto.

Desde una perspectiva constitucional, la interpretación del derecho de asociación cooperativa recogido en el artículo 22, no puede hacerse al margen del resto de la norma, que quedaría desvirtuada si tal derecho se interpretara en sus términos literales. Interpretación por otro lado conforme al principio de igualdad de los artículos $41^{29}$ y $44^{30}$, que

28 Rodríguez Musa, O.: «Marco jurídico de las cooperativas en Cuba. Tracto histórico y realidad actual», Deusto Estudios Cooperativos, núm. 14, 2019, p. 40.

29 Artículo 41: El Estado cubano reconoce y garantiza a la persona el goce y el ejercicio irrenunciable, imprescriptible, indivisible, universal e interdependiente de los derechos humanos, en correspondencia con los principios de progresividad, igualdad y no discriminación. Su respeto y garantía es de obligatorio cumplimiento para todos. Constitución de la República de Cuba. Gaceta Oficial de la República de Cuba, Edición Extraordinaria núm. 5, de 10 de abril de 2019.

30 Artículo 44: El Estado crea las condiciones para garantizar la igualdad. Educa a las personas desde la más temprana edad en el respeto a este principio. El Estado hace efectivo este derecho con la implementación de políticas públicas y leyes para potenciar la inclusión social y la salvaguarda de los derechos de las personas cuya condición lo requieran. Constitución de la República de Cuba. Gaceta Oficial de la República de Cuba, Edición Extraordinaria núm. 5, de 10 de abril de 2019. 
ordenan la interpretación extensiva de la protección constitucional del fenómeno cooperativo. Motivo por el cual, la interpretación del derecho de asociación cooperativa debe ser siempre de carácter garantista, de conformidad con el rango de derecho fundamental que le otorga la Declaración Universal de Derechos Humanos, de la cual Cuba es signataria ${ }^{31}$.

De igual manera, y a la hora de configurarse los cánones interpretativos al respecto, deben tenerse en cuenta otros apartados del texto constitucional como el artículo primero, el cual establece que «Cuba es un Estado socialista de derecho y justicia social, democrático, independiente y soberano, organizado con todos y para el bien de todos como república unitaria e indivisible, fundada en el trabajo, la dignidad, el humanismo y la ética de sus ciudadanos para el disfrute de la libertad, la equidad, la igualdad, la solidaridad, el bienestar y la prosperidad individual y colectiva». A su vez, el Preámbulo de la Constitución recoge «que Cuba no volverá jamás al capitalismo como régimen sustentado en la explotación del hombre por el hombre, y que solo en el socialismo y en el comunismo el ser humano alcanza su dignidad plena». Asimismo, el artículo 4 insiste en que «el sistema socialista que refrenda esta Constitución, es irrevocable». Motivo por el cual, en el Título XI relativo a la Reforma de la Constitución, se establece que en ningún caso resulta reformable el pronunciamiento relativo a la irrevocabilidad del sistema socialista ${ }^{32}$.

También han de ser tenidos en cuenta a la hora de completar el significado de lo que ha de ser un cooperativismo integral, los artículos 18 y 19, los cuales, respectivamente, señalan y desarrollan como «en la República de Cuba rige un sistema de economía socialista basado en la propiedad de todo el pueblo sobre los medios fundamentales de producción como la forma de propiedad principal, y la dirección planificada de la economía, que tiene en cuenta, regula y controla el mercado en función de los intereses de la sociedad»; así como que «la planificación socialista constituye el componente central del sistema de dirección del desarrollo económico y social. Su función esencial es proyectar y condu-

31 Artículo 20: 1. Toda persona tiene derecho a la libertad de reunión y de asociación pacíficas. 2. Nadie podrá ser obligado a pertenecer a una asociación. Declaración Universal de Derechos Humanos. Disponible en: https://www.un.org/es/universaldeclaration-human-rights/; última consulta: 1-04-2020.

32 Artículo 229: En ningún caso resultan reformables los pronunciamientos sobre la irrevocabilidad del sistema socialista establecido en el Artículo 4, y la prohibición de negociar bajo las circunstancias previstas en el inciso a) del artículo 16. Constitución de la República de Cuba. Gaceta Oficial de la República de Cuba, Edición Extraordinaria núm. 5, de 10 de abril de 2019. 
cir el desarrollo estratégico, previendo los equilibrios pertinentes entre los recursos y las necesidades». Asimismo, es importante señalar que, al amparo del artículo 20, «los trabajadores participan en los procesos de planificación, regulación, gestión y control de la economía».

Esta determinación de las personas trabajadoras a la hora de participar en los procesos de planificación, regulación, gestión y control de la economía en función de los intereses de la sociedad, debe incluir, por tanto, a aquellas organizadas en cooperativas de cualquier ámbito; las cuales podrán participar activa y conscientemente en la elaboración, aprobación y control del plan. En este sentido, «el desarrollo y el perfeccionamiento de la economía cubana, en los momentos actuales y como nunca antes, requiere del control y de la más amplia, activa y consciente participación y control de los trabajadores en la elaboración de los planes económicos y en el control de su cumplimiento, así como en la estimulación de su incorporación para lograr la conjugación de los intereses sociales, colectivos e individuales, además de otras tareas que constituyen la vía para el desarrollo de las relaciones socialistas de producción ${ }^{33}$. Debiendo recordarse a este respecto como, dentro del ideario marxista-leninista que inspira la propia Constitución, la organización de las personas trabajadoras en cooperativas constituye una forma superior de organización social.

De lo contrario, estaríamos olvidando que Cuba es un Estado socialista, en el que la soberanía reside «intransferiblemente en el pueblo», poder que se «ejerce directamente» ${ }^{34}$. Un principio que encuentra su origen histórico en quienes «promovieron, integraron y desarrollaron las primeras organizaciones de obreros, campesinos y estudiantes; difundieron las ideas socialistas y fundaron los primeros movimientos revolucionarios, marxistas y leninistas». El cual informa todo el sistema político, económico y social cubano.

El complemento y principal modo de expresión de este principio constitucional lo encontramos en el artículo 23 que determina la «pro-

33 Guerra Chacón, L.; lópez díaz, N.; Torres Magaña, M. P. y Pérez Bravo, D.: «El control y la participación de los obreros en la gestión económica en Cuba», en VV.AA.: La economía de los trabajadores: autogestión y distribución de la riqueza (RUGGERI, A., Coordinación), Ediciones de la Cooperativa Chilavert Artes Gráficas, Buenos Aires, 2009, p. 168.

34 Artículo 3: En la República de Cuba la soberanía reside intransferiblemente en el pueblo, del cual dimana todo el poder del Estado. El pueblo la ejerce directamente o por medio de las Asambleas del Poder Popular y demás órganos del Estado que de ellas se derivan, en la forma y según las normas fijadas por la Constitución y las leyes. Constitución de la República de Cuba. Gaceta Oficial de la República de Cuba, Edición Extraordinaria núm. 5, de 10 de abril de 2019. 
piedad socialista de todo el pueblo»y, tras negar que puedan «transmitirse en propiedad a personas naturales o jurídicas», permite "la trasmisión de otros derechos que no impliquen transferencia de propiedad sobre estos bienes», la cual se hará previa aprobación del Consejo de Estado, conforme a lo previsto en la ley, "siempre que se destinen a los fines del desarrollo económico y social del país y no afecten los fundamentos políticos, económicos y sociales del Estado» ${ }^{35}$. El artículo 24 también enumera otros bienes que también son «propiedad socialista de todo el pueblo», los cuales son «inembargables y pueden transmitirse en propiedad solo en casos excepcionales», cabiendo no obstante la «trasmisión de otros derechos sobre estos bienes, así como a su gestión» ${ }^{36}$.

Por su parte, el artículo 30 plantea que «la concentración de la propiedad en personas naturales o jurídicas no estatales es regulada por el Estado, el que garantiza además, una cada vez más justa redistribución de la riqueza, con el fin de preservar los límites compatibles con los valores socialistas de equidad y justicia social».

Lo anterior, señala PIÑEIRO HARNECKER, «no impide que cooperativas arrienden esos medios de producción fundamentales de las empresas estatales, como ya han venido haciendo las cooperativas agropecuarias

35 Artículo 23: Son de propiedad socialista de todo el pueblo: las tierras que no pertenecen a particulares o a cooperativas integradas por estos, el subsuelo, los yacimientos minerales, las minas, los bosques, las aguas, las playas, las vías de comunicación y los recursos naturales tanto vivos como no vivos dentro de la zona económica exclusiva de la República. Estos bienes no pueden trasmitirse en propiedad a personas naturales o jurídicas y se rigen por los principios de inalienabilidad, imprescriptibilidad e inembargabilidad. La trasmisión de otros derechos que no impliquen transferencia de propiedad sobre estos bienes, se hará previa aprobación del Consejo de Estado, conforme a lo previsto en la ley, siempre que se destinen a los fines del desarrollo económico y social del país y no afecten los fundamentos políticos, económicos y sociales del Estado. Constitución de la República de Cuba. Gaceta Oficial de la República de Cuba, Edición Extraordinaria núm. 5, de 10 de abril de 2019.

36 Artículo 24: La propiedad socialista de todo el pueblo incluye otros bienes como las infraestructuras de interés general, principales industrias e instalaciones económicas y sociales, así como otros de carácter estratégico para el desarrollo económico y social del país. Estos bienes son inembargables y pueden transmitirse en propiedad solo en casos excepcionales, siempre que se destinen a los fines del desarrollo económico y social del país y no afecten los fundamentos políticos, económicos y sociales del Estado, previa aprobación del Consejo de Ministros. En cuanto a la trasmisión de otros derechos sobre estos bienes, así como a su gestión, se actuará conforme a lo previsto en la ley. Las instituciones presupuestadas y las entidades empresariales estatales cuentan con otros bienes de propiedad socialista de todo el pueblo, sobre los cuales ejercen los derechos que le corresponden de conformidad con lo previsto en la ley. Constitución de la República de Cuba. Gaceta Oficial de la República de Cuba, Edición Extraordinaria núm. 5, de 10 de abril de 2019. 
que han gestionado tierra en usufructo gratuito por varias décadas y las nuevas cooperativas agropecuarias que arriendan locales, maquinarias y equipos» ${ }^{37}$.

De este modo, como indican Campos Pérez, García Pedraza y MartíNEZ MASSIP, «las cooperativas pueden relevar al Estado en la administración de aquellas actividades económicas, productivas o de servicios que no se consideren principales, y no solo en estas, sino también como apoyo a aquellas que el Estado no puede cubrir de manera suficiente o aun haciéndolo no con la calidad que se espera» ${ }^{38}$.

Vinculado al carácter socialista del Estado cubano, encontramos también el reconocimiento del derecho fundamental al trabajo como «un derecho, un deber social y un motivo de honor de todas las personas en condiciones de trabajar» ${ }^{39}$. De este modo, toda persona tiene derecho a que su trabajo se remunere en función de la calidad y cantidad del mismo, expresión del principio de distribución socialista «de cada cual según su capacidad, a cada cual según su trabajo». Principio jurídicamente jerarquizado que resulta coherente con el carácter participativo e inclusivo de la cooperativa ${ }^{40}$, como también lo son los valores constitucionales de justicia social, solidaridad e igualdad.

37 Piñeiro Harnecker, C.: «El futuro de las cooperativas en Cuba después de la Reforma Constitucional». Disponible en: http://autogestionrevista.com.ar/index. php/2019/07/22/dossier-cooperativas-para-actualizar-el-socialismo-en-cuba/?fbclid=IwA R1m8miq7LU12CsF6h5RsSAc WvmnE6Zlb8a1a55y2erWvpSQBPtgxI3XwVk; última consulta: 30-03-2020.

38 Campos Pérez, Y.; García Pedraza, L. y Martínez Massip, A.: «Las Cooperativas No Agropecuarias en Cuba: su trascendencia socioeconómica y jurídica», op. cit., p. 68.

39 Artículo 31: El trabajo es un valor primordial de nuestra sociedad. Constituye un derecho, un deber social y un motivo de honor de todas las personas en condiciones de trabajar. El trabajo remunerado debe ser la fuente principal de ingresos que sustenta condiciones de vida dignas, permite elevar el bienestar material y espiritual y la realización de los proyectos individuales, colectivos y sociales. La remuneración con arreglo al trabajo aportado se complementa con la satisfacción equitativa y gratuita de servicios sociales universales y otras prestaciones y beneficios. Constitución de la República de Cuba. Gaceta Oficial de la República de Cuba, Edición Extraordinaria núm. 5, de 10 de abril de 2019.

40 «En esta, por los principios solidarios y democráticos, el individuo tiene la doble condición de trabajador o perceptor del servicio y de socio y titular de una empresa; él es el que percibe los resultados directos justos - benéficos o adversos- del quehacer, en correspondencia al aporte del servicio cooperativo que realizan, no del aporte patrimonial. De tales cualidades le deviene su naturaleza socialista». Fernández Peiso, A.: La Cooperativa. Bases para su Legislación en Cuba, Editorial de Ciencias Sociales del Instituto Cubano del Libro, La Habana, 2012, p. 50. 
Un Estado socialista en el que "todas las personas son iguales» ${ }^{41} \mathrm{y}$ "la mujer y el hombre tienen iguales derechos y responsabilidades en lo económico, político, cultural, laboral, social, familiar y en cualquier otro ámbito» ${ }^{42}$.

En este sentido, y más concretamente en la profundización de una interpretación garantista y potenciadora del derecho de asociación cooperativa, interesa también una interpretación que, en palabras de HeRNÁndez Aguilar, permita «operar al Derecho, como elemento autorizante, ordenador y estimulante (...) de una mayor inclusión y empoderamiento de las mujeres dentro del sector cooperativo, a partir de una regulación que garantice los marcos adecuados para el desarrollo de todas las potencialidades sociales y culturales, más allá de las económicas, presentes en esta forma de emprendimientos económicos colectivos» ${ }^{43}$. Pues, como señala la propia autora, «las cooperativas tienen una especial aptitud para enfocar en su desarrollo un tratamiento de las cuestiones de género desde una perspectiva más favorable que otras formas empresariales, pues desde la configuración misma de sus principios están favorablemente condicionadas, solo es cuestión de aprovecharla de forma coherente y consecuente, partiendo para ello de una regulación legal afín con sus principios» ${ }^{44}$.

41 Artículo 42: Todas las personas son iguales ante la ley, reciben la misma protección y trato de las autoridades y gozan de los mismos derechos, libertades y oportunidades, sin ninguna discriminación por razones de sexo, género, orientación sexual, identidad de género, edad, origen étnico, color de la piel, creencia religiosa, discapacidad, origen nacional o territorial, o cualquier otra condición o circunstancia personal que implique distinción lesiva a la dignidad humana. Todas tienen derecho a disfrutar de los mismos espacios públicos y establecimientos de servicios. Asimismo, reciben igual salario por igual trabajo, sin discriminación alguna. La violación del principio de igualdad está proscrita y es sancionada por la ley. Constitución de la República de Cuba. Gaceta Oficial de la República de Cuba, Edición Extraordinaria núm. 5, de 10 de abril de 2019.

42 Artículo 43: La mujer y el hombre tienen iguales derechos y responsabilidades en lo económico, político, cultural, laboral, social, familiar y en cualquier otro ámbito. El Estado garantiza que se ofrezcan a ambos las mismas oportunidades y posibilidades. El Estado propicia el desarrollo integral de las mujeres y su plena participación social. Asegura el ejercicio de sus derechos sexuales y reproductivos, las protege de la violencia de género en cualquiera de sus manifestaciones y espacios, y crea los mecanismos institucionales y legales para ello. Constitución de la República de Cuba. Gaceta Oficial de la República de Cuba, Edición Extraordinaria núm. 5, de 10 de abril de 2019.

43 HeRnández Aguilar, O.: «La relación género y cooperativa en el ordenamiento jurídico cubano. Una aproximación a su realidad y a sus perspectivas ante el proceso de perfeccionamiento del modelo económico en el país», Boletín de la Asociación Internacional de Derecho Cooperativo, núm. 46, 2012, p. 317.

44 Ibidem, p. 305. 
De este modo, puede concluirse que existe base constitucional para el desarrollo integral del fenómeno cooperativo. Fenómeno que, tal y como ha quedado expuesto, "tiene una naturaleza socialista, que le viene dada por su origen, por su contenido y por sus fines», lo que le permitirá, «aún más en las condiciones de Cuba, materializar la solidaridad, la mutualidad, la valoración del trabajo, el beneficio común y los valores de una sociedad socialista» ${ }^{45}$.

\section{Formas asociativas para la diversificación y perfeccionamiento del sector cooperativo}

Partiendo (1) del reconocimiento constitucional de toda cooperativa "sustentada en el trabajo colectivo de sus socios propietarios y en el ejercicio efectivo de los principios del cooperativismo»; (2) ligado a una interpretación garantista y potenciadora del derecho de asociación cooperativa; (3) con base en los valores y principios promovidos por la Constitución cubana; (4) al objeto de diversificar y perfeccionar el sector cooperativo, mediante un amparo constitucional que impulse su desarrollo efectivo e integral; (5) incluyendo una mayor inclusión y empoderamiento de las mujeres dentro del sector cooperativo; (6) como parte del proceso de actualización del modelo socioeconómico cubano; (7) y en cumplimiento de las obligaciones del Estado socialista, el cual debe «encauzar los esfuerzos de la nación en la construcción del socialismo», "así como preservar y multiplicar los logros alcanzados por la Revolución»; se proponen, sin excluir otras posibilidades, las siguientes formas de tipo cooperativista: sociedades cooperativas de participación estatal, sociedades cooperativas depositarias de bienes propiedad del Estado, sociedades cooperativas tradicionales y sociedades cooperativas de grado superior.

Sociedades cooperativas de participación estatal

El artículo 26 de la Constitución cubana contempla como «el Estado crea y organiza entidades empresariales estatales con el objetivo de desarrollar actividades económicas de producción y prestación de servicios». Artículo que, si bien hace referencia a la empresa estatal socialista, recurriendo a una interpretación garantista y potenciadora del

45 Fernández Peiso, A.: La Cooperativa, op. cit., pp. 79 y 234. 
derecho de asociación cooperativa como la aquí planteada, puede incluir igualmente la creación de cooperativas de participación estatal que contribuyan a la producción y prestación de servicios, en diferentes sectores de la economía, a las que pueden cederse el uso y disfrute de bienes de propiedad estatal al amparo de los artículos 23 y 24 de la Constitución. Y ello, sin riesgo para el Estado, por cuanto el mismo artículo 26 dispone que «estas entidades responden de las obligaciones contraídas con su patrimonio», a la vez que «el Estado no responde de las obligaciones contraídas por las entidades empresariales estatales».

Para ello, puede recurrirse a fórmulas especiales o a entidades "suigeneris», basadas en los principios y valores del cooperativismo. Con ello, indican KAPLAN De DRIMER y DRIMER, «se procura democratizar la administración de las empresas nacionalizadas mediante la adopción de diversas fórmulas tripartitas o cuatripartitas (con representación de los consumidores agrupados en cooperativas, los asalariados, el Estado o Municipio, etc.); o bien (...) la organización de «régies coopératives», es decir, de entidades públicas o semi-públicas que (...) revisten algunos rasgos cooperativos» ${ }^{46}$.

Sociedades cooperativas depositarias de bienes propiedad del Estado

La Constitución de la República de Cuba contempla la posibilidad de transmitir «en propiedad solo en casos excepcionales, siempre que se destinen a los fines del desarrollo económico y social del país y no afecten los fundamentos políticos, económicos y sociales del Estado, previa aprobación del Consejo de Ministros» y/o «la trasmisión de otros derechos que no impliquen transferencia de propiedad sobre estos bienes».

De este modo, como señala RodríGuez Musa, «la Constitución concibe -excepcionalmente - la transmisión de la titularidad de los bienes de propiedad estatal, con presupuestos claros y rigurosos; pero la cooperativa puede avenirse cabalmente a ellos, en tanto se ofrezca el marco legal apropiado y la educación, capacitación e información que se requiere para garantizar su preocupación por la comunidad. Para dar cauce a esta estrategia, la transmisión puede ser cautelosa, si se tratare de objetivos económicos de significado valor e importancia, ya que la Constitución prevé (...) que la cesión no tiene que ser absoluta o tras-

46 Kaplan De Drimer, A. y Drimer, B.: Las cooperativas. Fundamentos, historia y doctrina, Intercoop Editora Cooperativa Ltda., Buenos Aires, 1973, p. 501. 
lativa de dominio, sino que puede limitarse a una transmisión parcial o solo del uso y disfrute sobre los bienes» ${ }^{47}$.

En palabras de Fernández PeISO, "esto no impugna que persevere la propiedad socialista de todo el pueblo sobre bienes y medios de producción y servicios, sino que se utilice esos bienes por cooperativas en variados sectores económicos, por medio de su transmisión mediante figuras legales capaces de otorgarle la imprescindible y plena seguridad jurídica de su independencia, autonomía y responsabilidad acompañante» 48 .

Posibilidad que viene reconocida en los apartados segundo y tercero del artículo $12^{49}$ del Decreto-Ley 366. A este respecto, el tercer principio cooperativo lo que indica, en relación al capital social, es que parte de ese capital es normalmente propiedad común de la cooperativa ${ }^{50}$. Por ello, que la propiedad de los medios fundamentales de producción de la cooperativa sea pública, no implica, a mi juicio, que no sea una verdadera cooperativa.

De este modo, indica Hernández Aguilar, "como Estado socialista, guiado por el pensamiento marxista, al cubano le corresponde

47 Rodríguez Musa, O.: La cooperativa como figura jurídica. Perspectivas constitucionales en Cuba para su aprovechamiento en otros sectores de la economía nacional diferentes al agropecuario, Editorial Dykinson S.L., Madrid, 2012, p. 74.

48 Fernández Peiso, A.: La Cooperativa, op. cit., p. 296.

49 Artículo 12: 1. Las cooperativas pueden constituirse a partir de los aportes dinerarios de personas naturales que deciden voluntariamente asociarse entre sí, de la forma siguiente: a) solo con el patrimonio constituido por esos aportes bajo el régimen de propiedad colectiva; o b) conservando los socios la propiedad sobre sus bienes. 2. También puede constituirse una cooperativa a partir de medios de producción del patrimonio estatal, tales como inmuebles y otros, que se decida gestionar como cooperativa y, para ello, esos medios pueden darse en arrendamiento, usufructo u otras formas legales que no impliquen la transmisión de la propiedad. 3. Además, la cooperativa puede constituirse por una combinación de las formas establecidas en los apartados 1 y 2 de este artículo. Decreto-Ley núm. 366, de las Cooperativas No Agropecuarias. Gaceta Oficial de la República de Cuba, núm. 63, de 30 de agosto de 2019.

50 «Los socios contribuyen equitativamente al capital de sus cooperativas y lo gestionan de forma democrática. Por lo menos parte de ese capital es normalmente propiedad común de la cooperativa. Usualmente, los socios reciben una compensación, si la hay, limitada sobre el capital entregado como condición para ser socio. Los socios asignan los excedentes a todos o alguno de los siguientes fines: el desarrollo de su cooperativa, posiblemente mediante el establecimiento de reservas, parte de las cuales por lo menos serian irrepartibles; el beneficio de los socios en proporción a sus operaciones con la cooperativa; y el apoyo de otras actividades aprobadas por los socios». ACl: Declaración de la Alianza Cooperativa Internacional sobre la Identidad Cooperativa. Los principios cooperativos, Consejo Superior de Cooperativas de Euskadi, Vitoria, 1996, pp. 17-19. 
estimular, con preferencia, las formas de producción y apropiación colectivas» ${ }^{51}$.

\section{Sociedades cooperativas tradicionales}

Como hemos visto, la Constitución de la República de Cuba protege a la cooperativa «sustentada en el trabajo colectivo de sus socios propietarios y en el ejercicio efectivo de los principios del cooperativismo", con independencia del sector de la economía en el que esta se desarrolle.

Si bien una interpretación literal del precepto constitucional citado podría llevar a una limitación a la hora de constituir cooperativas diferentes a las de producción, el criterio de interpretación que debe prevalecer es el de mayor amplitud posible del derecho de asociación cooperativa y la restricción del límite a lo necesario, lo que permitirá extender su protección a otras formas cooperativas, como las de consumo o crédito ${ }^{52}$, garantizando así la diversificación del sector cooperativo. Un reconocimiento que quedaría desvirtuado si se interpretara de manera restrictiva el derecho de asociación cooperativa.

\section{Sociedades cooperativas de grado superior}

Como advierte PIÑEIRO HARNECKER, «es importante plantearnos niveles superiores de organización socioeconómica, ya que estas instituciones son necesarias para coordinar las actividades productivas y así facilitar que satisfagan necesidades y aspiraciones de las mayorías»53. En este sentido, resulta necesario «regular el contenido y alcance de la libertad, los derechos, la responsabilidad y relaciones en la forma que se realizarán las actividades del sistema — producción, servicios, transformaciones, distribución, consumo, etcétera- por las cooperativas y de la intercooperación»; así como "garantizar la existencia y el funcionamiento de organizaciones representativas propias de las cooperativas, sean en el orden empresarial o social/ ${ }^{54}$.

51 Hernández Aguilar, O.: «Perspectivas institucionales y prácticas de las cooperativas en Cuba», Deusto Estudios Cooperativos, núm. 14, 2019, p. 148.

52 Piñeiro Harnecker, C.: Repensando el socialismo cubano. Propuestas para una economía democrática y cooperativa, Ruth Casa Editorial, La Habana, 2013, p. 155.

53 Piñeiro HarneCker, C.: «Prólogo», en VV. AA.: Cooperativas y socialismo: una mirada desde Cuba (PIÑEIRo HARnECKER, C., compiladora), Editorial Caminos, La Habana, 2011, p. 13.

54 Fernández Peiso, A.: «La Cooperativa», op. cit., pp. 195 y 196. 
En este sentido, no se trata solamente de crear un marco legal para asociaciones empresariales superiores como las cooperativas de segundo grado, sino de favorecer, jurídica e institucionalmente una unidad sociopolítica guiada por el propósito de defender, ayudar, promover y representar las cooperativas; así como de garantizar, mediante la auto-regulación y el auto-control, la responsabilidad social que le corresponde ${ }^{55}$.

A su vez, la regulación y promoción de las cooperativas de grado superior en Cuba, como indican Torga Hernández, Bencomo Fariñas y DelgADo RodRIGUEz, "puede ser muy útil para lo que se quiere lograr en nuestro país en estos tiempos, que es mantener las conquistas sociales de la Revolución y tener también eficiencia y sustentabilidad económica» ${ }^{56}$.

Los propios Lineamientos de la Política Económica y Social del Partido y la Revolución, aprobados en el VI Congreso del PCC, celebrado en abril de 2011, contemplaban por vez primera la creación de cooperativas de segundo grado ${ }^{57}$. Algo que encontró su reflejo en el Decreto-Ley núm. 305, de las Cooperativas No Agropecuarias ${ }^{58}$. Pero que, sin embargo, ha desaparecido del vigente Decreto-Ley núm. 366, de las Cooperativas No Agropecuarias.

Por ello, es necesario aprobar un marco normativo que legitime el funcionamiento de estas entidades en el contexto económico cubano.

55 Rodríguez MusA, O.: La constitucionalización de la cooperativa. Una propuesta para su redimensionamiento en Cuba, Vincere Associados, Brasil, 2017, p. 151.

56 Torga Hernández, N.; Bencomo Fariñas, Y. y Delgado Rodríguez, Y.: «Perspectivas para la constitución de cooperativas de segundo grado en Cuba», en VV.AA.: Apuntes de Derecho Cooperativo para Cuba (Rodríguez Musa, O. y HeRnÁndez Aguilar, O., coordinación), Ediciones Loynaz, Pinar del Río, 2018, pp. 242 y 244.

57 «29. Se crearán cooperativas de segundo grado, cuyos socios son cooperativas de primer grado, las que tendrán personalidad jurídica y patrimonio propio y se forman con el objetivo de organizar actividades complementarias afines o que agreguen valor a los productos y servicios de sus socios (de producción, servicios y comercialización), o realizar compras y ventas conjuntas con vistas a lograr mayor eficiencia». PCC: Lineamientos de la Política Económica y Social del Partido y la Revolución. Aprobados el 18 de abril de 2011. Disponibles en: http://www.cubadebate.cu/noticias /2011/05/09/descargue-encubadebate-los-lineamientos-de-la-politica-economica-y-social-pdf/\#.XMrZhtSLRnL; última consulta: 24-03-2020.

58 Artículo 5: 1. Las cooperativas pueden ser de primer o de segundo grado. 2. Es de primer grado la cooperativa que se integra mediante la asociación voluntaria de al menos tres personas naturales. 3. Es de segundo grado la cooperativa que se integra por dos o más cooperativas de primer grado con el objetivo de organizar actividades complementarias afines o que agreguen valor a los productos y servicios de sus socios, o de realizar compras y ventas conjuntas, con vistas a lograr mayor eficiencia. DecretoLey núm. 305, de las Cooperativas No Agropecuarias. Gaceta Oficial de la República de Cuba, Extraordinaria núm. 53, de 11 de diciembre de 2012. 
Este tipo de sociedades, como las previamente enunciadas, deben tener encaje en la interpretación garantista y potenciadora del derecho de asociación cooperativa.

\section{Conclusiones}

Al objeto de impulsar la diversificación y fortalecimiento del sector cooperativo en Cuba, resulta imprescindible una interpretación del texto constitucional que permita un desarrollo efectivo e integral del fenómeno cooperativo, en el marco del proceso de actualización del modelo socioeconómico cubano.

El amparo constitucional para un desarrollo efectivo e integral del fenómeno cooperativo, puede y debe sustentarse en el vigente texto constitucional mediante una interpretación garantista y potenciadora del derecho de asociación cooperativa, con base en los principios y valores promovidos por la propia constitución cubana. Entender lo contrario, vendría a contradecir el espíritu del texto, obstaculizando al mismo tiempo un desarrollo cooperativo efectivo e integral.

En definitiva, frente a la interpretación restrictiva del texto constitucional, debe prevalecer una interpretación garantista, a la vez que potenciadora, del derecho de asociación cooperativa en coherencia con la inspiración socialista del texto constitucional.

\section{Bibliografía}

ACl: Declaración de la Alianza Cooperativa Internacional sobre la Identidad Cooperativa. Los principios cooperativos, Consejo Superior de Cooperativas de Euskadi, Vitoria, 1996.

Campos Pérez, Y.; García Pedraza, L. y Martínez Massip, A.: «Las Cooperativas No Agropecuarias en Cuba: su trascendencia socioeconómica y jurídica», Deusto Estudios Cooperativos, núm. 14, 2019, p. 61-94.

ENGELS, F.: «Del socialismo utópico al socialismo científico», en MARX, K. y ENGELS, F.: Obras escogidas, Tomo III, Editorial Progreso, Moscú, 1980, pp. 98160.

Engels, F.: "Carta a A. Bebel», en Marx, K. y Engels, F.: Obras escogidas, Tomo III, Editorial Progreso, Moscú, 1980, pp. 28-34.

Fernández Peiso, A.: La Cooperativa. Bases para su Legislación en Cuba, Editorial de Ciencias Sociales del Instituto Cubano del Libro, La Habana, 2012.

Guerra Chacón, L.; lópez Díaz, N.; Torres Magaña, M. P. y Pérez Bravo, D.: «El control y la participación de los obreros en la gestión económica en Cuba», en VV.AA.: La economía de los trabajadores: autogestión y distribución de 
la riqueza (RUgGeRI, A., Coordinación), Ediciones de la Cooperativa Chilavert Artes Gráficas, Buenos Aires, 2009, pp. 157-172.

HeRNÁndez Aguilar, O.: «La relación género y cooperativa en el ordenamiento jurídico cubano. Una aproximación a su realidad y a sus perspectivas ante el proceso de perfeccionamiento del modelo económico en el país», Boletín de la Asociación Internacional de Derecho Cooperativo, núm. 46, 2012, pp. 297-320.

HeRnÁndez Aguilar, O.: "Perspectivas institucionales y prácticas de las cooperativas en Cuba», Deusto Estudios Cooperativos, núm. 14, 2019, pp. 143-164.

Kaplan De Drimer, A. y Drimer, B.: Las cooperativas. Fundamentos, historia y doctrina, Intercoop Editora Cooperativa Ltda., Buenos Aires, 1973.

LAMBERT, P.: La doctrina cooperativa, Intercoop Editora Cooperativa Limitada, Buenos Aires, 1970.

LeNIN, V.I.: «Sobre las cooperativas», en LeNIN, V.I.: Sobre las cooperativas, Editorial Progreso, Moscú, 1980, pp. 28-34.

LichTHeIM, G.: Breve historia del socialismo, Alianza Editorial, Madrid, 1970.

Martínez EtXeberRia, G. y Mata Diestro, H.: «Perspectivas para un cooperativismo socialista integral con base en los valores y principios promovidos por la Constitución cubana», en VV.AA.: Apuntes de Derecho Cooperativo para Cuba (Rodríguez Musa, O. y Hernández Aguilar, O., Coordinación), Ediciones Loynaz, Pinar del Rio, 2018, pp. 111-124.

MARX, K.: El Capital, Libro III, Tomo II, Editorial Akal, Madrid, 2000.

MARX, K.: "Crítica del programa de Gotha», en MARX, K. y Engels, F.: Obras escogidas, Tomo III, Editorial Progreso, Moscú, 1980, pp. 5-27.

MARX, K.: "La guerra civil en Francia», en MARX, K. y EnGels, F.: Obras escogidas, Tomo II, Editorial Progreso, Moscú, 1979, pp. 188-259.

MATA Diestro, H.: «Fondos sociales obligatorios: la justificación de su irrepartibilidad en los orígenes del cooperativismo y del movimiento obrero organizado», Boletín de la Asociación Internacional de Derecho Cooperativo, núm. 53, 2018, pp. 289-307.

Mata Diestro, H.: «Identidad cooperativa y economía socialista. Apuntes en torno a la relación dialéctica entre cooperativismo y socialismo». Ponencia presentada en el II Taller Internacional de Derecho Cooperativo, Universidad Hermanos Saíz Montes de Oca, Pinar del Río, Cuba, 2018.

Moreno Carvajal, T.; Medina Castillo, Y. M.; Medina, H. y Macias, L.: «La cooperativa agropecuaria cubana: valoración de sus presupuestos legales y funcionamiento». Disponible en: https://www.monografias.com/trabajos98/ cooperativa-agropecuaria-cubana-valoracion-sus-presupuestos-legalesy-funcio namiento/cooperativa-agropecuaria-cubana-valoracion-suspresupuestos-lega les-y-funcionamiento.shtml\#conclusioa; última consulta: 27-03-2020.

ONEI: Organización Institucional. Principales Entidades. Enero-marzo 2019, Oficina Nacional de Estadísticas e Información, La Habana, 2019.

PCC: Lineamientos de la Política Económica y Social del Partido y la Revolución. Aprobados el 18 de abril de 2011. Disponibles en: http://www.cubadebate. cu/noticias /2011/05/09/descargue-en-cubadebate-los-lineamientos-de-la- 
politica-economica-y-social-pdf/\#.XMrZhtSLRnL; última consulta: 24-032020

Piñeiro HaRneCKer, C.: «El futuro de las cooperativas en Cuba después de la Reforma Constitucional». Disponible en: http://autogestionrevista.com.ar/ index. php/2019/07/22/dossier-cooperativas-para-actualizar-el-socialismoen-cuba/? fbclid=IWAR1m8miq7LU12CsF6h5RsSAcWvmnE6Zlb8a1a55y2er WvpSQBPtgxl3XwVk; última consulta: 30-03-2020.

PiñeIRO HARneCKer, C.: "Prólogo», en VV. AA.: Cooperativas y socialismo: una mirada desde Cuba (PIÑERO HARNECKER, C., compiladora), Editorial Caminos, La Habana, 2011, pp. 7-30.

Piñeiro Harnecker, C.: Repensando el socialismo cubano. Propuestas para una economía democrática y cooperativa, Ruth Casa Editorial, La Habana, 2013.

Poisson, E.: La República Cooperativa, Editorial Cervantes, Barcelona, 1921.

Rodríguez MUSA, O.: La constitucionalización de la cooperativa. Una propuesta para su redimensionamiento en Cuba, Vincere Associados, Brasil, 2017.

Rodríguez Musa, O.: La cooperativa como figura jurídica. Perspectivas constitucionales en Cuba para su aprovechamiento en otros sectores de la economía nacional diferentes al agropecuario, Editorial Dykinson S.L., Madrid, 2012.

Rodríguez Musa, O.: «Marco jurídico de las cooperativas en Cuba. Tracto histórico y realidad actual», Deusto Estudios Cooperativos, núm. 14, 2019, pp. 17-44.

Torga Hernández, N.; Bencomo Fariñas, Y. y Delgado Rodríguez, Y.: «Perspectivas para la constitución de cooperativas de segundo grado en Cuba», en V.AA.: Apuntes de Derecho Cooperativo para Cuba (Rodríguez Musa, O. y Hernández Aguilar, O., coordinación), Ediciones Loynaz, Pinar del Rio, 2018, pp. 228-245.

TORRES ÁvILA, J.: «La teoría del Garantismo: poder y constitución en el Estado contemporáneo», Revista de Derecho, núm. 47, 2017, pp. 138-166.

\section{Legislación}

Constitución de la República de Cuba. Gaceta Oficial de la República de Cuba, Edición Extraordinaria núm. 3, de 31 de enero de 2003 (DEROGADA).

Constitución de la República de Cuba. Gaceta Oficial de la República de Cuba, Edición Extraordinaria núm. 5, de 10 de abril de 2019.

Declaración Universal de Derechos Humanos. Disponible en: https://www. un.org/es/universal-declaration-human-rights/; última consulta: 1-04-2020.

DeCRETO-LeY núm. 305, de las Cooperativas No Agropecuarias. Gaceta Oficial de la República de Cuba, Extraordinaria núm. 53, de 11 de diciembre de 2012 (DEROGADO).

DeCReto-Ley núm. 366, de las Cooperativas No Agropecuarias. Gaceta Oficial de la República de Cuba, núm. 63, de 30 de agosto de 2019. 


\section{Derechos de autor}

La revista Deusto Estudios Cooperativos es una revista de acceso abierto lo que significa que es de libre acceso en su integridad inmediatamente después de la publicación de cada número. Se permite su lectura, la búsqueda, descarga, distribución y reutilización legal en cualquier tipo de soporte sólo para fines no comerciales y según lo previsto por la ley; sin la previa autorización de la Editorial (Universidad de Deusto) o el autor, siempre que la obra original sea debidamente citada (número, año, páginas y DOI si procede) y cualquier cambio en el original esté claramente indicado.

\section{Copyright}

The Deusto Journal of Cooperative Studies is an Open Access journal which means that it is free for full and immediate access, reading, search, download, distribution, and lawful reuse in any medium only for non-commercial purposes, without prior permission from the Publisher or the author; provided the original work is properly cited and any changes to the original are clearly indicated. 